O Setor Elétrico é um dos que tem apresentado comportamento razoavelmente regular em meio à crise econômica recente.

As empresas que necessitam realizar pesados investimentos em geração, transmissäo e distribuição, particularmente as empresas geradoras e supridoras, com alto grau de expansão, decorrente do longo prazo de maturação de seus investimentos, foram estimuladas a captar recursos externos e têm sobrevivido à custa de endividamento crescente, uma vez que apenas as tarifas - contidas deste 1975 - não permitiram a auto-suficiência do Setor. Por mais adversa que tenha sido a política de viver à custa de empréstimo em moeda estrangeira, muitos deles com cláusulas vinculadas à compra de equipamentos no exterior e concorrências internacionais danosas para a indústria nacional, como para economia (efeito multiplicador), plena. mente capacitadas a atender as encomendas, ainda assim, por falta de opcão, parece que ela foi melhor do que a diminuição drástica dos investimentos que, diga-se de passagem, também nảo vêm crescendo em termos reais, cujos reflexos seriam altamente prejudiciais para a retomada do desenvolvimento econômico.

O problema de recursos, principalmente via tarifas reais, é agudo e a manutenção dessa política poderá ocasionar a deterioração dos serviços que o Setor Elétrico vem prestando à sociedade.

Para que o Setor Elétrico possa se adequar à necessária retomada do cres. cimento econômico, será preciso man. ter as tarifas em niveis reais e selecionar melhor os subsídios dados, com vistas, principalmente, à implementação de programas de conservação e substituição de energéticos importados.

Um sistema de subsídios, desde que bem planejado e criteriosamente definido, será vantajoso para o paĺs, pois se estará economizando divisas - problema financeiro básico - permitindo diminuir o grau de dependência externa, induzindo a uma mudança no sistema produtivo vigente, para um outro que melhor se amolde à realidade de um pais em desenvolvimento (carente de recursos fi. nanceiros), buscando encontrar padrões de consumo (bem-estar) condizentes com as necessidades básicas de crescimento do seu mercado interno.

\title{
Metodologia de previsão do mercado de energia elétrica
}

\section{PAULO DE VILHENA BRANDÃO}

Chefe do Departamento de Mercado da Diretoria de Planejamento e Engenharia da ELE. TROBRÁS.

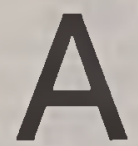
presenta-se, aqui, uma descrição sumária da metodologia atualmente adotada no tocante à previsão do mercado de energia elétrica no Brasil, com ênfa. se nos aspectos de longo prazo. No item 2. apontam-se algumas características gerais dos estudos de mercado, realiza. dos correntemente no Setor Elétrico. A seguir, são descritas, de forma sucinta, as abordagens metodológicas utilizadas para a previsão do consumo, por categoria (item 3) e dos requisitos de ener. gia e ponta (item 4).

\section{Caracteristicas gerais da metodologia utilizada}

A previsão do mercado de energia elé trica no Brasil, resulta de um processo iterativo, no qual a ELETROBRAS, que atua como coordenadora dos estudos, responsabiliza-se pela preparação de previsōes, a nivel nacional e regional, que servem como elementos balizadores na análise das previsões de mercado das 61 concessionárias, cujo controle acionário pode estar no nível federal, estadual municipal ou mesmo privado. Este fracionamento dos estudos de mercado decorre, sobretudo, das dimensōes continentais do país, que determina estrutu. ras sócio-econômicas e disponibilidades de recursos energéticos bastante diferenciadas entre regiōes e que, necessariamente, se refletem na configuração dos mercados de energia.

Os requisitos do mercado de energia elétrica são estimados com base em hi. póteses sobre a evolução provável de um conjunto de variáveis macro-económicas, demográficas e habitacionais e com base em informaçőes quanto a programas setoriais especificos, a nivel federal e estadual e quanto a novos contratos de suprimento de porte significativo. Leva-se em conta o comportamento pretérito do mercado, considerando, porém, além da tendência, eventuais distorções das series históricas, devidas à inadequação do atendimento no passado.

Complementando estas análises, realizam-se freqüentemente estudos especificos sobre os principais setores do mercado industrial, e sobre as possibilidades de racionalização do emprego dos recursos energéticos disponíveis, mediante adoção de mecanismos para promover a conservação e substituição, como, por exemplo, de derivados de petróleo por eletricidade.

O horizonte e o detalhamento das previsões, por tipo e localização do consumo, variam com a finalidade a que se destinam, tal como o planejamento dos sistemas geradores, de transmissão e de distribuição, para os quais são distintos o escopo e o prazo de maturação das decisões. Tendo em vista ainda que, para os primeiros anos da previsão, o volume e a confiabilidade das informações disponíveis são bem maiores do que para os demais, desdobra-se a análise da evolução do mercado em dois períodos básicos, aos quais aplicam-se critérios ligeiramente diferentes.

Para os primeiros três anos de estudos, o consumo por categoria, os indices de perdas, o fator de carga e vendas em grosso, são previstos, segundo metodologia especiffica, constante da Portaria 760 do DNAEE. Para o longo prazo (com horizonte de 20 a 30 anos), a principal referência adotada é o crescimen. to dos grandes agregados macroeconômicos e demográficos. A vinculação do consumo com os mesmos, particular. mente a elasticidade-renda, é o principal objeto de análise, uma vez que, dada à margem possível de variação destes, o consumo previsto pode sofrer alteraçōes substanciais. A variação da relação en tre os crescimentos do consumo e da renda reflete, essencialmente, alterações na na. tureza do mercado. Essa elasticidade será, tanto maior, quanto mais predomina. rem, entre os novos consumidores, aqueles de elevado consumo de energia elétrica por unidade de produto.

As previsões de longo prazo são elaboradas segundo metodologia que se caracteriza por: 
a) admitir, nas previsões referentes às regiões ou empresas, hipóteses comuns quanto ao crescimento global da economia e da população brasileira;

b) considerar o efeito de cargas especiais relevantes, em cada área de concessão, e seus possíveis efeitos multiplicadores;

c) considerar as possibilidades geoeconômicas de cada região e suas potencialidades em recursos naturais;

d) considerar as conseqüências de uma melhor distribuição de renda e da evolução tecnológica.

Assim, na avaliação do mercado não se consideram apenas as tendências verificadas, e, embora, em geral, as previsões sejam elaboradas de forma determinística, os valores dos parâmetros utilizados são ponderados subjetivamente e, conforme sua escolha, caracterizam os resultados como uma previsão provável, alta ou baixa, dos requisitos do mercado. Geralmente obtém-se, primeiro, uma projeção denominada provável, a partir da qual se obtém as demais, que, tradu. zindo hipóteses mais extremas, e conseqüêntemente menos prováveis, quanto ao comportamento das principais premissas levolução da economia, implementação de grandes projetos, e outros condicionantes), balizam as perspectivas da evolução da demanda.

\section{Provisōes por categoria de consumo}

A metodologia usual divide o mercado em 9 classes de consumo, definidas por instrumento legal, porém, de cunho eminentemente comercial: Residencial; In. dustrial; Comércio e Serviços; Rural; Iluminação Pública; Poderes Públicos; Serviços Públicos (subdivididos em Âgua, Esgoto e Saneamento e Tração Elétrica); Consumo Próprio e Canteiros de
Obras. Dessas classes, destacam-se a Industrial e a Residencial, que em 1985 , responderam por $75 \%$ do consumo de energia elétrica no país, conforme indica - Quadro I. Na discussão que se segue, maior atenção será dada a estes dois ægmentos.

\section{Consumo Residencial}

A projeção é obtida pelo produto das estimativas do número de consumidores residenciais e do consumo por consumidor residencial.

A projeção do número de consumidores é elaborada com base na evolução prevista do número de domićllios, resultante de estudo demográfico, e na projeção da taxa de atendimento, definida como a relação entre o número de consumidores residenciais e o número total de domićĺios. Na projeção da taxa de atendimento utiliza-se uma funçāo de saturação, em geral uma logistica do ti po:

$$
T A=\frac{k}{1+e^{a-b t}}
$$

onde: $\mathrm{TA}=\mathrm{Taxa}$ de atendimento

$$
\begin{aligned}
& k=\text { Assíntota estimada } \\
& t=\text { anos }
\end{aligned}
$$

A identificação dos parâmetros $\mathrm{K}$, a e b da área em questão, reflete: a tendência da série histórica e a estrutura final do número de domicflios, previsto no estudo demográfico; a consideração de diferentes hipóteses (formatos de curval, com referência ao desenvolvimento do processo de penetração de energia elétrica na área; e a consideração de fatores que representam rupturas, localizadas no tempo, do padrão de expansão "tradicional", em especial, programas de incorporaçāo de consumidores de baixa

\section{QUADRO 1}

\begin{tabular}{l|r|r}
\hline \multicolumn{3}{c}{ CONSUMO DE ENERGIA ELETRICA POR CLASSES, 1985} \\
\hline \multicolumn{1}{c}{ ESPECIFICAÇĀO } & GWh & $\%$ \\
\hline Industrial & 91.321 & 55,8 \\
Residencial & 32.635 & 20,0 \\
Comércio e Serviços & 18.526 & 11,3 \\
Iluminação Pública & 6.068 & 3,7 \\
Serviços Públicos (A.E.S.) & 4.394 & 2,7 \\
Poderes Públicos & 3.956 & 2,4 \\
Rural & 4.517 & 2,8 \\
Traçäo Elétrica & 1.132 & 0,7 \\
Consumo Próprio & 553 & 0,3 \\
Canteiro de Obras & 432 & 0,3 \\
TOTAL & 163.534 & 100,0 \\
\hline
\end{tabular}

Fonte: ELETROBRASIDEME/DVAM

renda, construção de grandes conjuntos habitacionais, expansão acentuada de áreas urbanas.

O consumo por consumidor residencial, é obtido levando-se em consideração:

a) a análise da tendência histórica;

b) a correção do efeito da absorção de novos consumidores de baixa renda e, conseqüentemente, baixo consumo (programas especiais):

c) a previsão de níveis cresœentes de saturação do consumo por consumidor, em função do crescimento esperado da renda e da capacidade de utilização de aparelhos eletrodomésticos, que possuam um uso mais intensivo de energia elétrica (ex.: ar condicionado).

Informações sobre o estoque de aparelhos eletrodomésticos e características domiciliares, são obtidas através dos Censos Demográficos da FIBGE, pesquisas do PNAD (FIBGE) e/ou através de pesquisa direta dos consumidores residenciais das respectivas áreas de concessão.

As previsōes da evolução do consumo por consumidor residencial, sāo comparadas a valores históricos ou projetados de outras empresas ou áreas com caracter/sticas semelhantes àquela que se está estudando.

\section{Consumo Industrial}

Para as previsões do consumo industrial, referentes a curto e médio prazos, o consumo total é separado em dois segmentos: um denominado tendencial, projetado a partir de sua evolução histórica, e outro, composto de grandes cargas que são estudadas individualmente, sendo em seguida agregadas às do estra. to tendencial.

A projeção do consumo das grandes cargas, é feita através de pesquisa direta e análise dos programas governamentais, para os setores mais representativos, tais como siderurgia, metalurgia, química, etc. Já o estrato tendencial é tratado de forma agregada, utilizando-se na sua previsão, uma função ajustante que traduza a evolução histórica e a influência das grandes cargas sobre a base econômica regional.

A longo prazo, a previsão do consumo industrial é realizada a nivel regio. nal, com base na correlação deste com a renda interna do setor secundário. O resultado desta correlação é tomado como batizador da evolução do consumo industrial total, definido como o consumo atendido, tanto por concessionárias. 
como por autoprodução. São, no entanto, realizados ajustes nesses resultados, em função das características da área em estudo e das informações específicas pertinentes ao efeito locacional das grandes cargas utilizadas nas previsões dos primeiros anos.

Em outros casos, é feita a separação do consumo por setores industriais, para os quais são elaboradas projeções, por tendência ou correlação, em função das hipóteses de crescimento da economia identificadas nos estudos de apoio.

Feita a definição da previsão do consumo industrial total por região, é retirada desse resultado a previsão da evolução da geração líquida dos autoprodutores, quando, então, é obtida a previsão do consumo industrial das concessioná. rias da região. A seguir, é analisada a evolução histórica da participação percentual do industrial de cada Estado, no total da energia elétrica industrial vendida pelas concessionárias na região. Com base nesta análise, é feita a projeção dessa participação nos anos seguintes. Processo semelhante é adotado para a desagregação do consumo industrial de cada Estado pelas concessionárias que nele atuam. Nestas análises são levados em consideração:

a) os efeitos multiplicadores de investimentos das grandes cargas industriais;

b) as políticas de desenvolvimento regional e estadual;

c) as perspectivas de evolução da renda e da população local;

d) os recursos naturais, principalmente no que se refere aos minerais.

Em resumo, pode-se dizer que a metodologia até aqui adotada pelo Setor, implica nos pressupostos de que, no curto e médio prazos, o comportamento do mercado industrial:

1) "está relativamente pouco condi. cionado d̀s perspectivas de evolução ma. croeconômica;

2) ex explicado, principalmente "em função de medidas específicas, na maioria conhecidas individualmente, tais como a instalação de novas cargas indus. triais";

3) é explicado, também, pelo comportamento pretérito do mercado (feitos ajustes para levar em conta eventuais distorções das séries históricas)' 1 .

Já, no longo prazo, a relação entre consumo de energia elétrica e renda, torna-se 0 indicador básico utilizado nas

1. GCPS/CTEM, "Metodologias empregadas nas previsð̃es do mercado de energia elétrica", p.1.2 previsões do mercado industrial para as principais concessionárias. Para as demais, o mercado é projetado por correlação temporal, por correlação com o mercado total ou através da análise individual de cargas de grande porte.

Consumo das Classes Comercial e Serviços, Poderes Públicos, Iluminação Pública e Água, Esgoto e Saneamento.

As previsões de consumo destas quatro classes, são usualmente obtidas por correlação com o consumo residencial. No caso da classe Comercial e Serviços, trata-se, separadamente, cargas que, pelo seu porte, alterem esta correlação. Para a classe dos Poderes Públicos é usada, como abordagem alternativa, a extrapolação da tendência histórica.

Já a previsão do consumo de lluminação Pública utiliza três tipos de abordagem: correlação com o consumo residencial, extrapolação da tendência histórica e informações sobre programas especŕficos de expansão dos serviços, da parte das concessionárias ou das prefeituras.

O consumo de Iluminação Pública, também, tem sido obtido a partir do produto das projeções do número de consumidores residenciais e do Indice watts de iluminação pública por consumidor residencial, este último, quando possível, tratado como o produto dos indices watts/poste e poste/consumidor residencial.

Para projetar o consumo em Água, Esgoto e Saneamento são avaliadas as cargas dos sistemas de abastecimento de água e das instalações de recalque e tratamento de esgotos, considerando-se, em geral, nos primeiros anos, as cargas de projeto. Para os anos seguintes, utiliza-se uma correlação com o consumo residencial, ou com o número de consumidores residenciais ou mesmo a extrapolação da tendência histórica de evolução deste segmento de consumo.

Demais classes: Consumo Rural, de Tra. cão Elétrica, Próprio e de Canteiros de Obras

O consumo rural é projetado a partir da tendência histórica e dos programas de eletrificação rural das concessionárias, das cooperativas, dos órgãos municipais, regionais e federais. De forma semelhante, o consumo em tração elé. trica é projetado a partir da evolução verificada e dos programas de instalaçāo e expansão desses serviços.
O consumo próprio refere-se à energia consumida pela concessionária e mantém, em geral, uma participação percentual aproximadamente constante em seu mercado. Já o consumo de canteiros de obras é projetado a partir da programação de obras das concessionárias.

\section{Consumo Total}

O consumo total é obtido somandose as categorias de consumo. Expresso, por exemplo, em GWh, corresponde ao fluxo de energia entregue aos consumidores ao longo de um ano. Nos estudos de longo prazo, não se considera o consumo interno das usinas no mercado das empresas concessionárias, uma vez que suas projeções destinam-se, principalmente, a estudos de planejamento, nos quais aquele consumo é deduzido da produção bruta das usinas. Já nos estudos de curto prazo, este consumo integra a previsão de mercado.

\section{Previsăo dos Requisitos de Energia e de Ponta}

\section{Requisitos de Energia}

Os requisitos anuais de energia, expressos em geral em MWano ou em GWh, correspondem ao fluxo de energia fornecida pelo sistema supridor, durante o ano. Caso este suprimento seja referido à salda das usinas, tais requisitos incorporam, em sua definição, além das estimativas de consumo, uma estimativa das perdas do sistema de suprimento. Estas, por sua vez, são constiturdas de perdas técnicas e de diferenças contábeis, que podem existir em decorrência de regimes de suprimento a "forfait" (sem medição direta), consumo mínimo faturado, etc.

Nos estudos do sistema elétrico brasileiro, os requisitos de energia são apresentados, excluindo as perdas nos troncos de transmissão das grandes empresas supridoras, pois sua estimativa dependeria de uma projeção de intercâmbio lou vendas em grossol e da produção das usinas, que variam segundo as condições hidrológicas e outros condicionantes da operação interligada. Assim, os índices de perdas projetados se referem aos sistemas de distribuição, subtransmissão $\theta$ transmissão, até os seguintes niveis de tensão:

Região Norte - $69 \mathrm{kV}$ exclusive perdas do sistema ELETRONORTE

Região Nordeste $-230 \mathrm{kV}$ exclusive perdas do sistema CHESF 
Regiões Sudeste

e Centro-Oeste -- $230 \mathrm{kV}$ exclusive perdas do sistema FURNAS

Região Sul - $230 \mathrm{kV}$ exclusive perdas do sistema ELETROSUL.

No dimensionamen to das perdas e di. ferenças do sistema, analisa-se a série histórica do índice de perdas, as distâncias médias de transmissão, os programas de reforma das redes, e ainda, a evolução verificada e prevista dos suprimen. tos em grosso e do fornecimento a "forfait".

\section{Requisitos de Ponta}

Enquanto o consumo e energia cor respondem a conceitos de fluxo, a ponta de carga corresponde a um conceito de estoque, indicando a potência máxima requerida pelo sistema de suprimento no ano, em função da qual deverá ser feito o dimensionamento da capacidade dos sistemas elétricos (consideradas ainda as reservas necessárias ao adequado funcionamento do sistema).

A energia fornecida, ou consumida, num sistema elétrico a cada unidade de tempo, na realidade, distribui-se irregularmente ao longo de um dado perfodo. Esta distribuição pode ser expressa por uma curva de carga que terá formato irregular, como na Figura 1. presso em MWano $\div$ ano, por um fator de carga, que expressa a relação entre a demanda média requerida e a ponta ou demanda máxima verificada ou esperada no mesmo período.

O fator de carga é estudado em cada caso particular. Procura-se correlacionálo com a estrutura do mercado suprido e as características das cargas que compõem este mercado. Usualmente, emprega-se uma correlação linear múltipla, entre o fator de carga e a participacão das três principais categorias de consumo (residencial, comercial e industrial) no consumo global. O resultado dessa correlação, mesmo que nåo forneça um valor muito confiável para o fator de carga, dá indicações úteis quanto à tendência de sua evolução.

Para a análise da capacidade de um sistema interligado de suprimento elétrico, o que se deseja efetivamente é um dimensionamento da demanda máxima coincidente ou ponta simultânea que poderá ocorrer no sistema num dado período. Face às dificuldades de se estimar a configuração futura da curva de carga de um sistema interligado e, mesmo, face aos problemas de diversidade de horário de ocorrência da demanda máxima entre seus integrantes, a definição dos requisitos de ponta apresenta

\section{FIGURA 1}

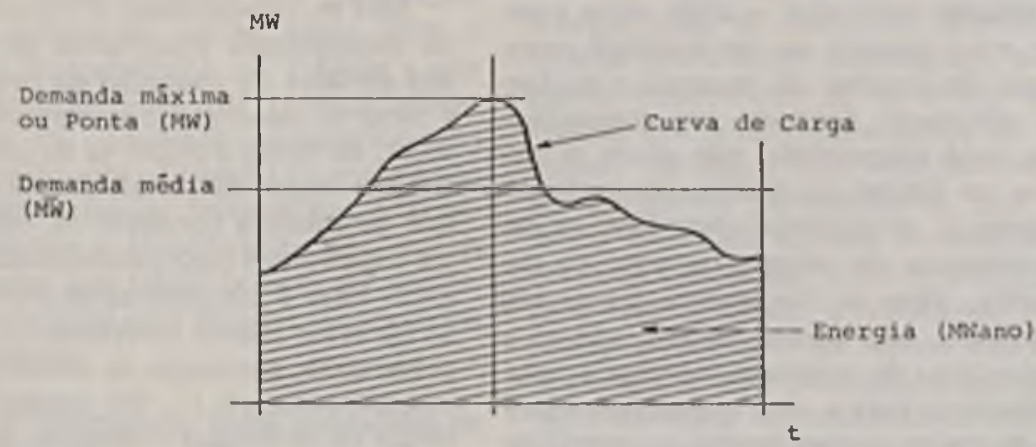

timos tratados de forma integrada, já que constituem um único sistema de suprimentol - e para as empresas integrantes destes, introduz-se um fator de diversidade, através do qual se estima a ponta "simultânea" de cada um. Esta traduz a contribuicão de cada empresa à formação da ponta do sistema regional.

A partir da introdução de tarifas horo-sazonais, os valores históricos de fator de carga e, de um modo geral, a forma das curvas de carga registradas dos sistemas em que essas tarifas sejam utilizadas, perderam, em parte, sua representantividade. Conseqüentemente, os estudos de previsão de demanda máxima terão que se valer de "modelos $\boldsymbol{x}$. toriais" de avaliação da evolução da forma da curva de carga, bem como de outros instrumentos analíticos, que supram a falta de informações estatísticas representativas de configurações futuras dessas curvas. Pode-se adiantar, todavia, que a tendência é, certamente, no sentido do aumento do fator de carga, em função da utilização da referida tarifa.

\section{BIBLIOGRAFIA}

1. Alquéres, J.L. et alii, "Metodologia de planejamento do Setor Elétrico". CIERI Comitẻ Brasileiro/Subcomitè de Planejamento e Engenharia de Sistemas Elétricos, Maio de 1985

2. Erber, P. et alii, "Metodologia empregadas nas previşōes do mercado de energia elétrica". "ELETROBRÁS/DEME, IT. 426. janeiro de 1983.

3. Girod, J., La Demande d'Energie: Methodes et Techniques de Modelisation. Paris: Centre National de la Recherche Scientifique, 1977

4. MME/DNAEE. "Metodologias para Projeḉes de Mercado". Anexo da Portaria 760 , Junho de 1976.
A este fornecimento de energia IMW ano) está associada uma demanda ou carga média ( $(\overline{\mathrm{MW}})$, que é a potência que, se fosse utilizada uniformemente ao longo do mesmo perlodo, forneceria montante de energia equivalente àquele descrito pela curva de carga referida.

Os requisitos de ponta resultam da divisão da demanda média, ao longo de um perlodo (um ano, por exemplo) MW, ou seja, requisitos de energia, ex. uma dificuldade maior do que a dos de energia.

Para a Região Norte, cujo suprimento é feito predominantemente por um conjunto de sistemas isolados, os requisitos de ponta correspondem ao somatório simples das pontas dos sistemas integrantes, independente, portanto, do instante de sua ocorrência. Já, para os grandes sistemas regionais - Nordeste, Sul, Sudeste e Centro-Oeste (estes dois últi- 